\title{
Corpus
}

Archivos virtuales de la alteridad americana

Vol. 9, No 2 | 2019

Julio / Diciembre 2019

\section{Grutas y altares moralizados. 0 de cómo territorializar las muertes violentas en sectores populares (Córdoba, Argentina)}

Grottos and altars moralized. Or how to territorialize violent deaths in popular sectors (Córdoba, Argentina)

\section{Natalia Bermúdez}

\section{OpenEdition}

\section{Journals}

\section{Electronic version}

URL: http://journals.openedition.org/corpusarchivos/3267

ISSN: 1853-8037

\section{Publisher}

Diego Escolar

\section{Electronic reference}

Natalia Bermúdez, « Grutas y altares moralizados. O de cómo territorializar las muertes violentas en sectores populares (Córdoba, Argentina) », Corpus [En línea], Vol. 9, No 2 | 2019, Publicado el 26 diciembre 2019, consultado el 28 diciembre 2019. URL : http://journals.openedition.org/ corpusarchivos/3267

This text was automatically generated on 28 December 2019.

Licencia Creative Commons: Atribución-NoComercial 2.5 Argentina (CC BY-NC 2.5 AR) 


\section{Grutas y altares moralizados. $\mathrm{O}$ de cómo territorializar las muertes violentas en sectores populares (Córdoba, Argentina) ${ }^{1}$}

Grottos and altars moralized. Or how to territorialize violent deaths in popular sectors (Córdoba, Argentina)

Natalia Bermúdez

\section{EDITOR'S NOTE}

Fecha de recepción del original: 30/09/2019

Fecha de aceptación para publicación: 13/11/2019

\section{Palabras introductorias}

1 En el corazón del barrio Los Cortaderos, frente a una canchita de fútbol de tierra y de un salón cooperativo, se pueden encontrar dos murales, uno pintado antes del asesinato del Güeré y otro poco tiempo después, en alusión a su muerte. El mismo Güeré participó de la elaboración del primero que parece haber sido premonitorio, jóvenes representados como peces con gorras, siendo perseguidos, vigilados y atrapados por las redes de otros peces más poderosos, simbolizando a los policías. Portación de rostro, vestimenta, barrio y apellido resultan así los etiquetamientos más frecuentes que operan como mecanismos de exclusión y de legitimación de detenciones arbitrarias y de abusos policiales dirigidos hacia los jóvenes pobres.

2 Al poco tiempo, Güeré fue asesinado por dos uniformados. Fue ahí cuando sus amigos planearon la realización de otro mural y de la gruta. ${ }^{2}$ Un mural que interpela a sus 
visitantes a partir del rostro del Güeré pintado en primer plano acompañado por la frase "llévame un solo instante a tu presencia que tu ausencia duele intensidades. Quién hubiera pensado que te fueras si tu vida en flor era una fiesta". Repleta de recuerdos, imágenes religiosas, cartas y fotografías, la gruta de dos pisos, con puertas de vidrio y rejas negras se fue convirtiendo de ahí en más en un lugar de encuentro neurálgico para el barrio.

3 Tatuajes, altares, grafitis, murales y grutas forman parte de las cada vez más frecuentes prácticas de conmemoración que familiares, amigos y vecinos desarrollan en torno a los jóvenes muertos en villas y barrios de sectores populares cordobeses. Especialmente los altares y grutas conjugan una serie de referentes tanáticos, dispositivos seculares y religiosos que permiten recordar la muerte, resignificarla y denunciarla públicamente.

El asesinato del Güeré, como el de tantos otros, visibiliza algunos de los entramados que me interesará problematizar en este artículo, vinculados a clasificaciones sociales y morales en torno a las muertes y desapariciones que los familiares y vecinos afrontan, a prácticas de patrimonialización de las muertes violentas (Flores Martos, 2014) y a procesos de territorialización y moralización de las mismas en altares y grutas.

5 La investigación etnográfica y comparativa que vengo desarrollando desde 2007 aborda redes de relaciones familiares, sociales y políticas vinculadas a muertes en contextos de violencia en sectores populares de la ciudad de Córdoba. Acompañar a familias y vecinos a los cementerios, marchas y misas en las fechas conmemorativas, así como estar presente en charlas y reuniones en calles, patios y viviendas, fueron las actividades más importantes del trabajo de campo. He realizado además numerosas entrevistas en profundidad a madres y padres de jóvenes muertos producto de la violencia policial, de la inseguridad o de los denominados ajustes de cuentas, para diversos proyectos académicos. Este escrito también forma parte de actividades de investigación dialógica (Aguiar Bittencourt, 2004) e intervención entre la universidad y distintas organizaciones con familiares de víctimas para la creación de una muestra de imágenes itinerante. ${ }^{3}$

\section{Violencias, territorio y pobreza}

Pondré una lente especial en este trabajo sobre los años noventa, debido a que en esta etapa neoliberal comienza a acentuarse la criminalización de los pobres, en especial de los y las jóvenes, de la mano de la consolidación del problema de la inseguridad urbana y de la "nueva delincuencia" (Kessler, 2009). Ligado al crimen y a los modos más "eficaces" de su represión, los medios masivos contribuyeron también al afianzamiento de esta problemática social centralizando su preocupación en el reclamo de "mayor seguridad" de los sectores medios y altos. Como señala María Pita, el discurso sobre la seguridad urbana, "formulada en términos de razón de Estado (Tiscornia, 2000), definió la clave de lectura en torno a la violencia, ocluyendo así, simultáneamente, el cuestionamiento a la expansión del poder policial y los abusos y arbitrariedades que de él resultan" (Pita, 2010, p. 46).

7 Desde entonces podemos observar cómo específicamente en la provincia de Córdoba se ha venido promoviendo una progresiva "policiación" del gobierno y del manejo de la "seguridad" (Hathazy, 2014), buscando resoluciones cada vez más penalizantes que terminan por generar y/o profundizar los procesos de violencia y segregación socio- 
territoriales que atraviesan los sectores más empobrecidos económicamente (Bermúdez, 2014).

8 Es en este contexto que, sumado a la escasez de recursos materiales y sociales y al consumo de drogas, la represión policial abusiva, el encarcelamiento y los conflictos entre grupos locales (Epele, 2007 y 2010) han ido propiciando un proceso de normalización del morir siendo joven en los sectores populares urbanos.

9 Se trata entonces de jóvenes estigmatizados en vida, y cuya desaparición o muerte los vuelve a colocar bajo esta misma posición. En estos marcos sociales y culturales, solo una víctima de inseguridad es asumida socialmente como una víctima "inocente", mientras que a estos jóvenes que son asesinados en barrios y villas consideradas como zonas peligrosas se les adjudica la condición de sospechosos y a sus muertes la de cierto merecimiento. Así las muertes etiquetadas como ajuste de cuentas, ligadas a violencias "horizontales", nos revelan que tanto al muerto como al asesino se les reserva socialmente la misma predestinación y condición amoral. También los abusos policiales desplegados en barrios, villas o en lugares de encierro aparecen como prácticas legítimas para algunos sectores sociales (Bermúdez, 2016). Las víctimas terminan siendo responsabilizadas por sus vínculos - no siempre reales- con actividades vinculadas al delito menor o a la economía informal. Es decir que aquello que puede designarse ampliamente como violencia, resulta acompañado de percepciones bien diferenciadas que generan diversas posiciones políticas y sociales respecto al tratamiento dado, tanto a la víctima como a sus familiares, de un gran impacto sobre la vida de las personas (Birman y Pereira Leite, 2004).

Sumado a ello, un restringido mercado laboral imposibilita el acceso tanto a recursos básicos como al reconocimiento social para estos jóvenes, por lo que "la exposición física, la valentía y resistencia que son parte de un estilo de vida conflictivo pueden volverse las bases personales de la dignidad" (Míguez, 2012, p. 261). Las diversas construcciones identitarias que desarrollan las y los jóvenes en lo cotidiano pueden comprenderse tanto a partir de las violencias institucionales, sociales y simbólicas que los atraviesan, y de las que ellos mismos hacen uso, como de las apropiaciones territorializadas de sus espacios barriales más próximos. Así las esquinas, los pasajes y calles de sus barrios se convierten en lugares de pertenencia no "tradicionales", de reconocimiento y autoafirmación social (Míguez, 2012; Previtali, 2018; Chaves, 2010, Cozzi, Font y Mistura, 2014; entre otros). Apropiaciones que se entienden no solo en relación al paso intermitente por otras instituciones como la escuela o el trabajo, sino también en concordancia con las políticas segregatorias que dificultan que los jóvenes consigan salir de las villas y barrios que habitan sin ser detenidos. Es en estos territorios que las muertes violentas de los jóvenes terminan siendo, como veremos, territorializadas y moralizadas.

11 Los jóvenes varones a los que conozco desde hace más de una década, a través de mi trabajo de campo, han perdido varios amigos en estos entramados, son los que ocupan las cárceles de la provincia repletas de pobres, y conjugan actividades de la economía ilegal con trabajos informales principalmente en la construcción. Solo algunos consiguen terminar el primer nivel escolar, y otros pocos el nivel secundario. Quienes están en ese último grupo pueden optar por asegurarse un sueldo básico inscribiéndose en la policía, enfermería u otros oficios poco rentables.

12 Ahora bien, resulta interesante indagar cómo estas transformaciones estructurales en la pobreza vienen acompañadas de significativos cambios al interior de estos sectores. 
Tanto Míguez (2008 y 2012) como Carozzi (2006) se dedican a analizar cómo el campo religioso, por ejemplo, acompasó este tránsito por diversas etapas, en tanto reelaboraciones de sentido a partir de los cuales los sectores más afectados por la crisis de los años 90 buscaban adaptarse a ella. Podemos observar la relativa emergencia de procesos de santificación, como San La Muerte o el Gauchito Gil, ${ }^{4}$ debido a la potencialidad que tienen estas figuras de expresar universos morales divergentes. Se produce así una "progresiva desnaturalización del orden legal convencional y cierta adopción de la transgresión de la norma social convencional, como el delito" (Míguez, 2012, p. 243). De igual modo, los investigadores encuentran en Buenos Aires casos de jóvenes en conflicto con la ley canonizados, y señalan que en esta operación pueden verse algunos "desplazamientos" respecto de estos formatos tradicionales. La más emblemática sería la canonización del Frente Vital (un joven abatido por la policía en la zona norte del Gran Buenos Aires en el año 2000), dado que sus seguidores no hacen ningún esfuerzo por justificar sus acciones contrarias a la ley. Las nuevas devociones favorecen un orden moral "en el que los estilos de vida poco convencionales e incluso la ilegalidad se vuelen más naturales y aceptables” (2012, p. 243). Aunque, como señala Míguez, y como veremos en este trabajo, se trata de cambios relativos que no implicaron el desmoronamiento absoluto de modelos tradicionales de vinculación y representación social.

13 A partir del trabajo de campo que vengo realizando, he analizado etnográficamente cómo las grutas, altares y murales dedicadas a los jóvenes muertos -que no siempre implican canonizaciones como las descriptas por Míguez- involucran experiencias de devoción como horizonte de posibilidades de una trama moral y religiosa más amplia (Bermúdez, 2018). Los santuarios se convierten en espacios atravesados por prácticas de devoción y especialmente de sacralización, ${ }^{5}$ siguiendo a Martín (2007). Pero lejos de buscar abarcar la complejidad y riqueza de estas prácticas, he priorizado aquí el análisis de la proliferación de estas especies de santuarios, en el marco de los procesos de activismo familiar y barrial, de búsquedas de diversas formas de justicia y de territorialización de la muerte. Los hallazgos etnográficos que sustentan este énfasis me han permitido discutir la homogeneización con que la academia tiende a analizar los repertorios políticos de los familiares de víctimas, reduciéndolos a la búsqueda de la justicia oficial (Bermúdez, 2015). Veremos aquí que la proliferación de santuarios comprende procesos de afectación de valores colectivos, usualmente "convencionales", que con la muerte o con la desaparición han sido confrontados. No hago referencia a que las muertes no presenten ambigüedades morales, ni que órdenes "no convencionales", al decir de los autores citados, hayan quedado fuera de las trayectorias de vida de los jóvenes, o de la de sus vecinos y amigos que los homenajean. Sino que, en todo caso, a partir de la territorialización de la muerte, se da relevancia a algún sentido desde el cual la muerte debe ser interpretada, leída, y por ende, conmemorada.

Con tales afirmaciones no pretendo señalar que la cultura de los grupos populares se produzca como respuesta mecánicamente a las fuerzas dominantes. Especialmente Míguez y Semán (2006), pero también Fonseca, hacen mención al peligro de la "resistencia reificada", cuando "se reduce el modo de vida de la población estudiada a sus aspectos reactivos" (2005, p. 124). Antes bien, recupero aquí los aportes de los estudios que resaltan la heterogeneidad cultural de los grupos populares urbanos remitiéndonos a su producción simbólica activa, es decir, a "una cultura producida por grupos populares" (Semán, 1997, p. 133) siempre en relación de articulación y 
conflictividad con otras clases sociales, y que las herramientas antropológicas nos permiten explicar situacionalmente. Parto, con Fonseca, de la importancia de pensar cuestiones de clase "en los márgenes", en los "flujos" y "entre-lugares" para evitar la reificación de los grupos populares de la sociedad contemporánea (2005, p. 119).

de su hijo muerto sobre el asfalto. Como epígrafe decía: "Una rata menos en la Colón". Cada vez que lo relata se angustia tanto que le lleva varios minutos recomponerse para poder volver a hablar. Este mensaje condensa el posicionamiento de buena parte de la sociedad cordobesa, y en especial de la mayoría de los comerciantes del barrio donde fuera asesinado. "Mi gran error", dice Gabriela cuando parece contestarle a quienes anónimamente mandaron la foto, "fue salir a trabajar todo el día para mantener a mis hijos, porque estoy sola". Este mensaje para Gabriela desconoce también la generosidad de Rodrigo con todos, pero especialmente con su hermana, que tiene una enfermedad crónica; su alegría, su esfuerzo para terminar la secundaria, el inicio de un curso de hotelería y turismo, y la pasión que le ponía cada vez que tenía que ir al club a jugar al fútbol. Omite, entre otras cosas, todo el sacrificio que ella hizo para acompañarlo a los partidos, bajo el frío y la lluvia. Ella siempre estuvo. Cada vez que Gabriela presenta su caso en el marco de la Muestra "Entre altares y pancartas", dice:

yo no niego que mi hijo se equivocó, que estaba robando una billetera. No lo niego.

Pero mi hijo tenía derecho a seguir viviendo. En todo caso tendría que estar preso.

Por eso lucho, por el derecho a la vida de mi hijo.

idero necesario, en esta dirección, problematizar cómo estos cambios que vengo describiendo en torno a la pobreza, el "problema" de la inseguridad y el delito han reverberado sobre las representaciones y prácticas que dentro de los mismos grupos populares y de otras clases sociales se generan en torno a estas muertes, y más específicamente, cómo vienen incidiendo sobre los procesos en los que familiares y allegados buscan visibilizar las muertes, tornarlas condenables, y en algunos casos, convertirse en activistas.

Las estigmatizaciones de clase también se ponen en juego cuando no encuentran a sus hijos luego del recorrido por numerosas comisarías, o bien toda vez que las autoridades judiciales les niegan el acceso a los cuerpos durante días o se los entregan "a cajón cerrado" y los familiares los encuentran "matados como a perros, golpeados, moretoneados, magullados, sin uñas" (Bermúdez, 2016). Se condensan también cuando reciben malos tratos, acusaciones y responsabilizaciones por lo ocurrido no solo en las 
oficinas de tribunales durante el largo derrotero judicial que se abre tras estas muertes, sino en los propios barrios a los que pertenecen. $\mathrm{O}$ cuando las noticias de los medios masivos tergiversan los relatos privilegiando siempre la versión policial. A fuerza de degradantes experiencias cotidianas a lo largo de sus trayectorias de vida, pero particularmente tras una muerte o desaparición, los familiares asumen, reflexionan, contestan y cuestionan aquellas contiendas morales que atraviesan sus casos.

21 A pesar de estas vivencias con fuertes efectos sobre sus subjetividades, algunas de estas madres consiguen convertirse en "activistas familiares" (Pita, 2010) e inician un trabajo simbólico, social y político para reclamar justicia en el que, como he venido señalando, no solo tienen lugar las marchas, las tramitaciones cotidianas y las adhesiones a diversas organizaciones sociales, sino también la construcción de altares y de grutas.

\section{Altares familiares y grutas barriales}

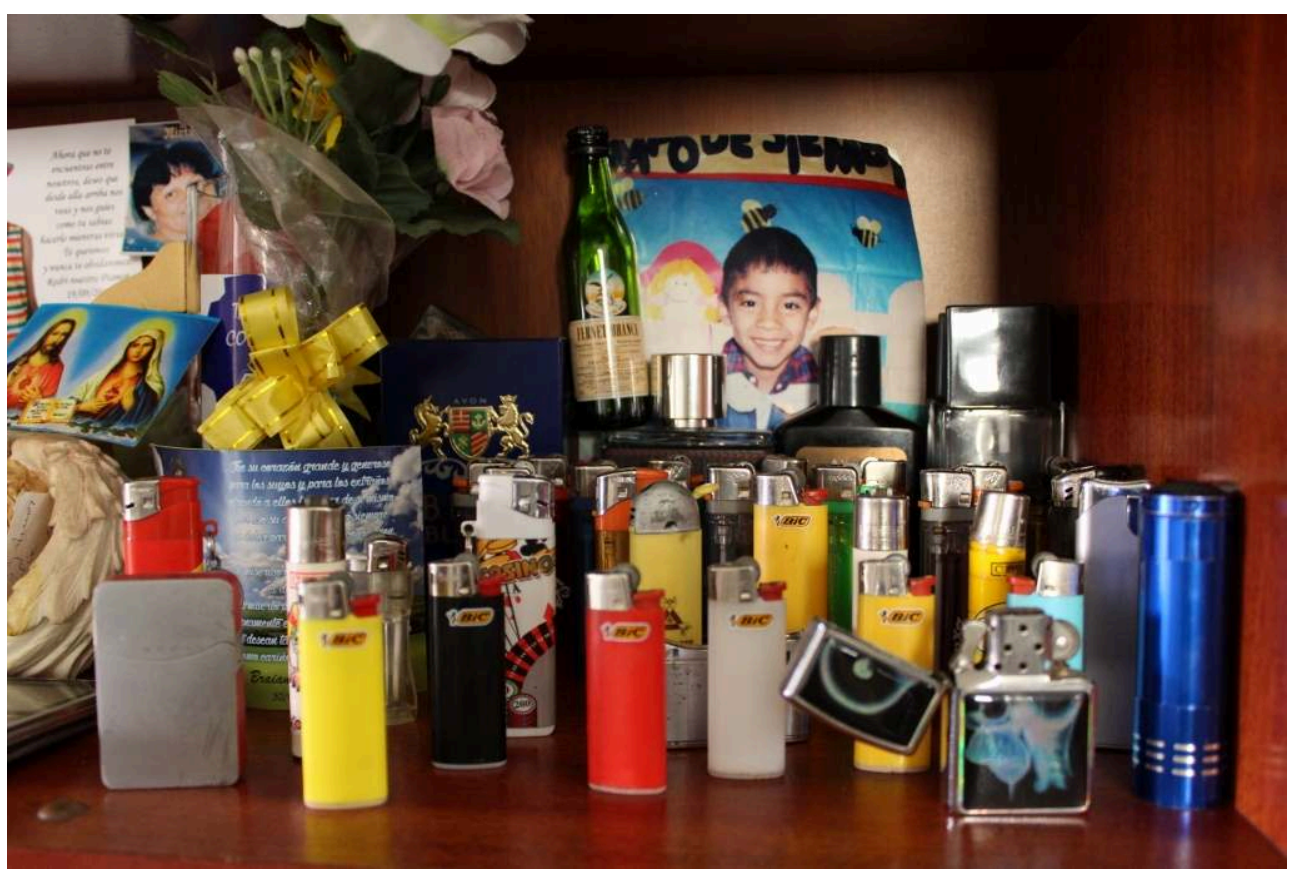

IMAGEN N ${ }^{\circ}$ 1. "Rodrigo coleccionaba encendedores. Yo los acomodo todos los días. Al fondo está su perfume. A veces lo echo sobre la almohada para tenerlo presente" (Gabriela, 2017). Foto tomada por Evelin Muñoz.

Había conocido a Gabriela el día en que inauguramos la muestra itinerante en la Legislatura. Se presentó y nos invitó a su casa porque quería sumar su "caso". Dos meses después Gabriela nos esperaba a mi compañera y a mí en la puerta del cementerio San Jerónimo para guiarnos. Una vez que se subió al auto nos dijo: “mi hijo está acá, pero yo no vengo nunca. Pero es una tortura porque desde la ventanita de mi casa lo veo".

Apenas cuatro cuadras después llegamos a su casa de Alberdi, barrio al que se mudó hace pocos años. Entramos por un patio común a varios departamentos de planta baja. Abrió la puerta, nos invitó a sentarnos y encendió la hornalla de la cocina para poner la pava, y nos dijo:

C2019-12-09T18:01:00CTodo lo que yo pueda hacer para mantenerlo vivo a mi hijo lo voy a hacer. Yo no soy tonta, sé que mi hijo no está, pero para mí tenerlo en la calle 
es mantenerlo vivo... Rodrigo vivió poquito [así es como define su trayectoria y por eso todo lo que hace]. No voy a descansar, para mantenerlo vivo de alguna forma.

Sobre la mesa había mantas, telas e hilados, que Gabriela hizo a un lado para acomodar la yerbera. Había empezado un curso para aprender a coser y tejer en una escuela religiosa que le costeaba los pasajes de ómnibus. Cada vez que Gabriela abría alguna puerta del mueble del comedor para buscar los elementos del mate, se caían los más de veinte encendedores que su hijo coleccionaba y que ella disponía prolijamente una y otra vez en el altar que le había armado, donde además sobresalían flores, fotos, recuerdos y un perfume de una reconocida marca de venta por catálogo. El mismo perfume que usaba su hijo, y que Gabriela vuelca todas las noches sobre su almohada antes de dormir para poder sentir su olor y soñar con él. Rodrigo tenía altar, no tenía gruta.

Los altares se dirigen especialmente a (re) introducir a los muertos -o más bien a la nueva presencia de los muertos-, en el ciclo de la vida familiar. Resultan las primeras demarcaciones íntimas que siempre aparecen tras una muerte en el interior de las viviendas, ubicadas en los espacios más públicos como comedores o cocinas. Sobre heladeras o aparadores desplazados de sus funciones habituales y acompañados por velas, flores y objetos religiosos, en estos altares las fotografías de los jóvenes muertos son interpeladas cotidianamente con diálogos y saludos. Prácticas como la renovación constante de objetos e imágenes nos remiten también a manifestaciones de atención y cuidado permanentes. Allí son colocadas tarjetas de aniversarios y cumpleaños, adornos de Navidad, juguetes, dientes caídos de los más pequeños de la casa, perfumes, monedas, objetos de colección del muerto. Los altares acompañan los tiempos de duelo familiar por lo que, a lo largo de los años, van ocupando distintos lugares dentro de la casa y en ciertos casos se van reduciendo hasta quedar pocas fotografías colgadas de alguna pared.

Pero solo algunas muertes y desapariciones consiguen ser inscriptas también "puertas afuera" de las viviendas o en los espacios más significativos para la vecindad, en grutas, conforme a procesos de construcción de memorias emprendidos por familiares o por organizaciones sociales. Aunque tales inscripciones barriales se producen especialmente cuando un asesinato confronta valores morales y la indignación es barrial. Las grutas entonces (re)sitúan a sus muertos en esas territorialidades fuertemente disputadas y apropiadas, es decir, en esa calle, en ese pasaje, en la canchita de fútbol.

Uno de los relatos que sintetiza lo que los familiares y allegados expresan cuando comienzan a armar las grutas es el de Jorge, hermano de Exequiel. El 24 de marzo de 2014 Exequiel, de 20 años de edad, fue golpeado y baleado por un policía vestido de civil. Exequiel tenía 20 años de edad y vivía con sus padres y con dos de sus cinco hermanos en Villa Boedo, un barrio de la zona sur de la ciudad de Córdoba. Cuando recorrimos el barrio nos mostraron el mural que hicieron frente a la casa en conmemoración de su muerte con la cara y la leyenda: Justicia x Exequiel. A pocos pasos visitamos la gruta.

Mientras retiraba pacientemente y con dedicado detalle cada uno de los objetos ubicados en la gruta para limpiarla, Jorge nos contaba:

los murales y las grutas son moda en Córdoba, porque es una forma de demostrarle a la policía cada vez que pasa que los pibes que ellos llevan no los olvidamos nosotros, siguen siendo recordados y queridos por nosotros. Los pibitos no se juntan más acá porque la policía los corre. La policía nos quiere hacer olvidar. Pero no nos vamos a olvidar nunca. 
Y volvió a acomodar dos virgencitas de yeso de distinto tamaño, el mate de madera de Exequiel y su cenicero, y sobre el fondo, la foto de su hermano.

Las grutas involucran producciones estéticas, conmemorativas, amorosas, políticas y también se articulan con las temporalidades de las memorias, de tramitación del dolor y de demanda de justicia. Implican tanto prácticas de contemplación, habitación y tránsito como de evitación espacial. Elaboradas por familiares, vecinos y allegados, gran parte de las grutas se suman inmediatamente a la simiente de la vida barrial. Otras, en cambio, ocupan espacios más periféricos o apegados a las redes familiares que los mantienen en pie.

Varias condiciones explicarían por qué Rodrigo, hijo de Gabriela, no tiene gruta. Como expuse, hacía pocos años que Gabriela se había mudado al barrio aledaño al cementerio. Para los vecinos de su actual barrio, Gabriela era considerada madre de una rata. Las nuevas redes vecinales le negaban la posibilidad de tornar la muerte condenable e imposibilitaban, por tanto, sostener la construcción de una gruta como homenaje.

2 Su lugar de crianza era aquel que compartía con el amigo de su hijo, quien salió a robar en moto aquel día, y a quien Gabriela acusara de traidor. A un año de la conmemoración del asesinato de Rodrigo, Gabriela junto a familiares de la Coordinadora ${ }^{6}$ y otras organizaciones sociales se dirigieron a la casa del amigo de su hijo luego de marchar en tribunales. Gabriela ya lo había ido a buscar varias veces y le había suplicado que declarara que no habían usado armas, situación que cambiaría la causa judicial. Tras este último episodio, Gabriela fue acusada por la familia del joven y por algunos vecinos del barrio de zarpar ${ }^{7}$ la casa. Esta acusación implicó que Gabriela y su familia resultaran reposicionados como vigilantes ${ }^{8}$ y su reclamo referido a un acto violento de invasión que incluso envolvió a actores considerados externos. ¿Cómo sería posible entonces territorializar la muerte de Rodrigo "puertas afuera"? Gabriela encarnaba, tras lo sucedido, reputaciones doblemente deslegitimadas.

3 Lo dicho hasta ahora sugiere que las redes de relaciones sociales más cercanas a los muertos cumplen un rol destacado en tanto fundamentos o recursos de sus prácticas dirigidas a construir una territorialidad de la muerte. ${ }^{9}$ Resulta necesario considerar además las reputaciones de los vivos y de los que fallecen, y las contiendas morales que entraman y terminan encuadrando las muertes violentas.

4 Es en esta dirección que sostengo que especialmente los altares y las grutas se establecen de alguna manera como portales ${ }^{10}$ de los márgenes ${ }^{11}$ donde se puede comprender de manera privilegiada cómo las clases subalternas pueden imaginar(se) y (re)crearse desde sus propias versiones y experiencias frente a la vida y a la muerte, en diálogo y confrontación con la sociedad más amplia. Allí, como veremos, se resignifica la muerte, moralizándola. ${ }^{12}$

En lo que sigue mostraré cómo se gesta esta territorialidad en relación con las contiendas morales que se disputan en cada caso, a partir de las muertes del Güeré, de Emiliano, y de la desaparición de Facundo.

\section{La gruta frente a la canchita de fútbol para Güeré trabajador}

No fue necesario bucear demasiado para averiguar qué había sucedido con Güeré. De gran repercusión mediática, las derivaciones de su muerte involucraron a autoridades policiales, periodistas y otros actores políticos, por lo que su caso se había mantenido en la escena pública durante varios meses. 

luego se habían ido a tomar algo a la casa de su abuelo, que vive también en el barrio. Cerca de las dos de la madrugada, el Güeré y Emiliano fueron a comprar más bebidas a un almacén en motocicleta. Llegando a la casa se cruzaron con un móvil policial de frente y siguieron de largo. El policía que conducía el patrullero disparó sin dar la señal de alto. El primo cayó al piso inmediatamente con una herida en la pierna, y Güeré siguió conduciendo. Nuevos disparos le terminaron por dar en la espalda hasta que también se desplomó y a los pocos minutos falleció. No asombró demasiado a sus vecinos la situación vivida, dado que ese policía era conocido en la zona por maltratar a los jóvenes varones del barrio.

Según los vecinos presentes aquella noche ninguno de los dos policías atendió a los heridos sino que regresaron tiempo después acompañados de otros móviles con gran cantidad de uniformados. Si bien tenían la intención de ingresar a la vivienda del abuelo, terminaron desistiendo cuando vecinos y familiares empezaron a tirarles piedras e insultarlos.

efión sicial sostenía que los jóvenes habían estado robando armados en las inmediaciones, y que habían disparado contra el móvil policial. La prueba sería la marca en la parte trasera del auto de un supuesto disparo. Sin embargo, en el juicio en el que se sentenció a cadena perpetua a los agentes policiales como autores del homicidio, se probó que los jóvenes no habían disparado y que tampoco tenían armas.

41 De hecho, durante los días posteriores a la muerte de Güeré, un periodista del canal de la universidad recogió varias declaraciones que sostenían que los uniformados habían intentado conseguir un arma en un taller de la zona para "plantársela" a los jóvenes. A partir de la circulación de esta información, el periodista fue amenazado por un funcionario policial, situación que desembocó en una denuncia en la Justicia, y su posterior imputación y procesamiento.

Podríamos decir que Sonia, madre de Emi y tía del Güeré, se convirtió en "activista familiar" (Pita, 2010). Su trayectoria previa como militante y referente vecinal resultó crucial para movilizar la búsqueda de justicia. Dispuesta a mostrarnos el barrio con profundo detalle y aquellos espacios vividos por su sobrino, nos esperó una tarde en su casa.

Caminamos primero pocas cuadras hasta una despensa en la que uno de sus hijos nos vendió una gaseosa. Seguimos luego hasta un galpón semi-abierto donde algunos jóvenes fabricaban macetas de cemento. En la pared de enfrente se podía leer en un grafiti: Güeré x siempre. Pregunté si allí había trabajado Güeré y Sonia me respondió: "no, acá trabajaban sus amigos y uno de sus hermanos".

Después continuamos rumbo a la gruta construida en el medio de espacios bien nutridos de gente y participación cotidiana. Aquella gruta de la que todos los vecinos habían querido formar parte porque Güeré era muy querido. Ciertamente, la gruta vidriada deja entrever cantidad de imágenes religiosas, cartas, medallitas y objetos variados en los dos pisos que la estructuran. 


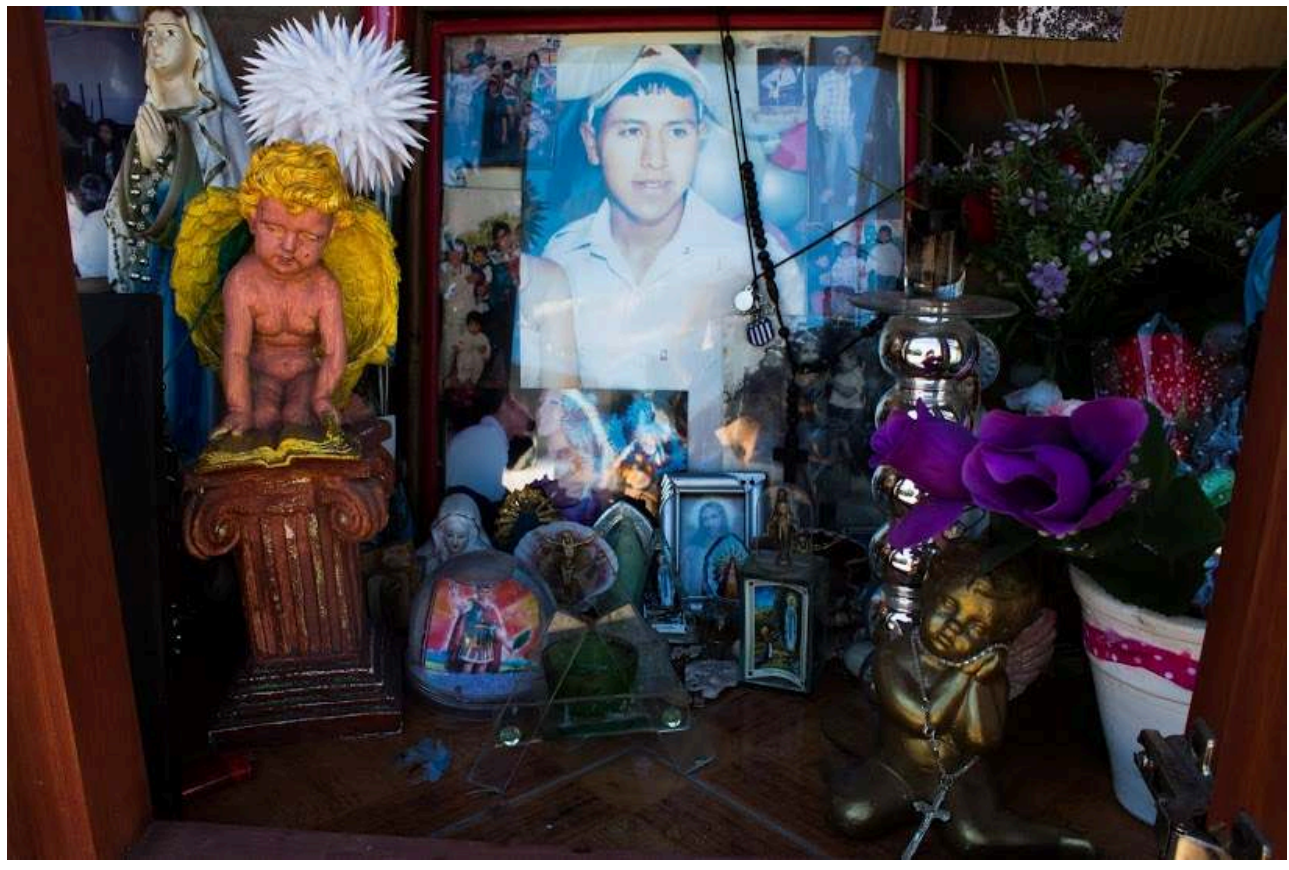

IMAGEN 2. "Cada vecino trajo algo para ponerle a la gruta" (amigo del Güeré). Foto tomada por Ayelén Koopmann.

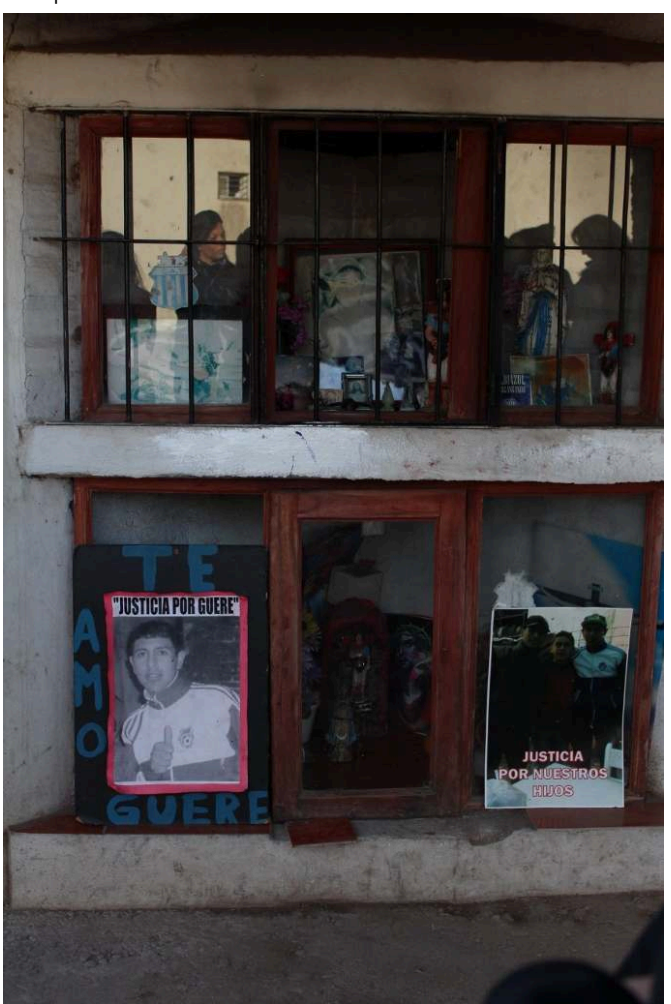

IMAGEN 3. "Yo no vengo muy seguido a la gruta, me hace mal", decía Curu, la mamá del Güeré. Foto tomada por Ayelén Koopmann.

45 Mientras tomábamos fotografías según nos indicaran, se acercó uno de sus amigos y nos fue explicando con detalle quiénes habían traído los objetos y por qué. Cada uno estaba anclado a una vivencia compartida con Güeré, a una anécdota, a un recuerdo que los unía: “esta estampita la puso su mejor amigo, esta medallita la vecina de enfrente, 
este dibujo se lo trajo el nene de la esquina. Yo le traje un recuerdito de cuando éramos chicos...".

Sonia, preocupada porque viniera todo el grupo de jóvenes, se movía inquieta con el celular en la mano. Una y otra vez nos explicaba que a esa hora "los chicos todavía están trabajando" en los cortaderos, oficio que ha caracterizado al barrio por más de cincuenta años.

La caminata continuaría. Seguía a unas cuadras de la gruta, precisamente en uno de los cortaderos de ladrillos del barrio. Le pregunto -insistentemente- a Sonia, ¿acá trabajaba Güeré? Con paciencia me respondió una vez más: "no, trabajaba en otro más alejado. Pero yo quiero que vean este, quiero mostrarles cómo trabajan los chicos del barrio. Sobre todo porque la gente de afuera no sabe".

¿Qué era aquello que Sonia se esmeraba en hacernos notar -y que a mí me costaba tanto entender-? Lejos de estar preocupada por ofrecernos la prueba documental que registrara cuáles habían sido los lugares significativos para Gabriel, Sonia buscaba demostrarnos algo más relevante aún, en tanto universitarias, profesionales, venidas de "afuera". Con este recorrido, Sonia inscribiría a su sobrino Güeré, a los amigos de su sobrino, y en ese mismo acto, a su propio hijo, en aquellas moralidades legitimadas socialmente que vinculan la dignidad al trabajo y al sacrificio. Güeré había sido asesinado siendo - y a pesar de ser- "trabajador, bueno y querido por todos".

Tanto el recorrido por el barrio como la gruta y los objetos allí ubicados -desde los que refieren a sus gustos, como a aquellos ligados a los sistemas de creencias de sus allegados- no podrían ser escindidos de aquellos aspectos de la biografía del joven que los allegados y vecinos buscan hiperbolizar. En contraposición con las versiones policiales que lo señalaran como delincuente, es entonces en esos sentidos enlazados al Güeré como trabajador que las prácticas en torno a su muerte y el territorio materializan la continuidad de la relación (re)construida, sostenida, homenajeada, mantenida viva (Bermúdez, 2018). La gruta, como lugar de reunión, re-incorpora al joven en esta sociabilidad barrial cotidiana. Territorio "es siempre representación social del espacio, espacio fijado, y espacio de fijación”, dice Segato (2006, p. 76). Reinscribir a los jóvenes muertos en lugares significativos para el barrio consiste entonces en anclar la muerte y su sentido en los territorios de los jóvenes, desde sus propias memorias, versiones, emociones y experiencias locales.

\section{La gruta en el pasaje para Emi traicionado}

A diferencia de Güeré, Emiliano "andaba en la joda". ${ }^{13}$ Emi fue baleado en octubre de 2007 en barrio el Palomar, y a las pocas horas murió en uno de los hospitales públicos de la ciudad de Córdoba.

Para muchos de los vecinos esta muerte era esperable precisamente porque andaba. Las primeras versiones que circularon sostenían que Emiliano había muerto por causa de los disparos en un enfrentamiento que, junto a su amigo Ariel, habían protagonizado contra una bandita de chicos de un barrio colindante. En el diario de mayor tirada en Córdoba apareció el caso como "ajuste de cuentas".

Sin embargo, todos los vecinos supieron que las cosas habían sido diferentes cuando la policía fue a la villa a detener a Ariel. Nadie se esperaba semejante desenlace que explicaba de alguna manera por qué había sido una muerte tan sentida por todos. Emi habría sido muerto por su propio amigo. Estas nuevas pruebas ofrecieron herramientas 
para reinterpretar el comportamiento de Ariel tras lo acontecido e, incluso, para dudar de la existencia misma de la amistad.

Victoria, madre de los primos y mejores amigos de Emiliano, era una de las más indignadas. Poco tiempo después de la muerte de otro joven en el barrio -esta vez a causa de un disparo accidental mientras jugaban con un arma-, Victoria, su hija y una vecina, establecían comparaciones mientras yo les cebaba mates. La muerte de Emiliano, era la más sentida según debatían, pero no solo porque les resultaba próxima a sus relaciones de parentesco. Decía Victoria:

Esa traición me cambió la vida a mí. Fue muy duro. Esto de que Ariel, su amigo, fuera el que lo mató. Todos lo queríamos tanto al Emi. Y era su amigo, y no dijo nada que había sido él... Lo que más me molesta es la traición, él fue al cementerio, lloraba y todo. Yo no voy a ser nunca más la misma. Lo que me jode es que fue por traición. Y después de lo que pasó... no dijo nada Ariel, mirá yo lo maté, fue sin querer, hasta fue al entierro el caradura. ¡Yo lo escondí en mi casa unos días! Todo eso a mí me puso muy mal el corazón, ahí te pones a pensar, si vale la pena luchar por los chicos de acá, si vale la pena porque uno se pone mal y trata de hacer cosas, pero es tan difícil.

Ariel había cumplido con una serie de obligaciones para con el muerto -y para los que quedan vivos, como nos advierte Malinowski (1986) - como llorar, ir al cementerio y mostrarse acongojado según las expectativas del vínculo de amistad que los uniría. A la luz de una "nueva verdad" judicial, tales demostraciones revelaron el engaño que inauguró una usina de preguntas y desconfianzas. ¿Qué es lo que podría haber desatado semejante traición?

La ruptura de un valor moral primordial y fundante entre los jóvenes, como lo es la amistad, implicó mayor gravedad y dolor que otras muertes, sucedidas incluso en circunstancias similares. Victoria decía encontrarse en una situación de deuda con el joven muerto porque había creído que escondiendo a Ariel en su propia casa lo estaba ayudando a Emi. Pero una vez que la policía fue a buscar a Ariel, algunas posiciones, sobre todo la suya, debieron ser redefinidas. Victoria debió dejar en claro su situación para no ser culpada de complicidad. Ella también había sido víctima del engaño de Ariel.

Junto a sus hijos, a algunos amigos y a los padres de Emi, Victoria fue una de las principales hacedoras de la gruta. Ubicada frente a su casa y a espaldas de la canchita de fútbol, la gruta de Emiliano era la única que había encontrado construida puertas afuera en aquella villa. ${ }^{14}$ 


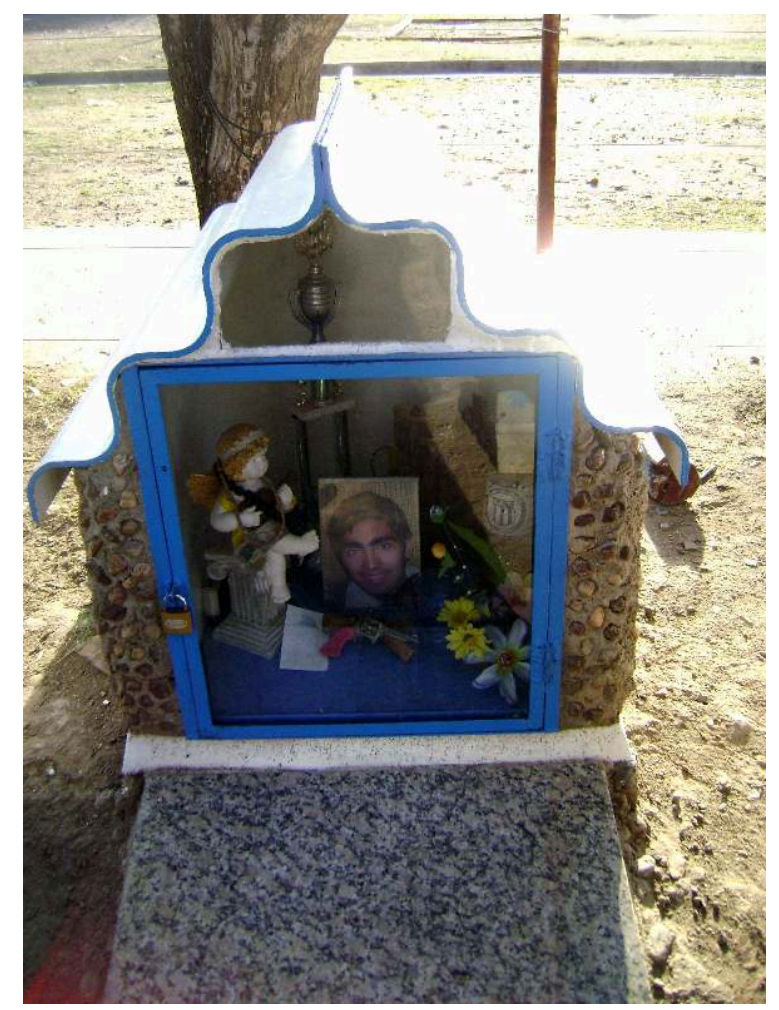

IMAGEN 4. "La hicimos entre todos", me decía su primo mientras sacábamos la foto.

Se dispusieron una serie de objetos dentro de la gruta: sobre la izquierda, la figura de un ángel de yeso con dos rosarios en su cuello, la copa del club de fútbol Talleres y un premio obtenido en un campeonato de fútbol por los chicos de la villa, sobre la derecha. En el centro, un vaso con bebida blanca, las estampitas que van diseñando para las misas en las fechas de conmemoración de su muerte y un arma pequeña conocida como matagato.

Tales objetos operaron representando a su persona, otorgando algunos indicios de los gustos y preferencias de Emi. La exaltación de su masculinidad introducida en la gruta por la presencia de ciertos objetos vinculados al fútbol, el arma y una bebida fuerte, resultan simbólicamente eficaces para mostrar a Emi como un joven con valor. Otros también visibilizaron las demostraciones de sus familiares y verdaderos amigos, descubriendo a Emi como un joven muy querido por todos, como un joven de buen corazón.

He trabajado ya cómo estos significados fueron movilizados como propios de la contrafigura del traidor (Bermúdez, 2015), oponiéndose así al asesino de Emi. Asiendo las interpretaciones de los símbolos e íconos visibilizados en la gruta, no había duda sobre quién era quién.

61 A diferencia de otras muertes, la gruta de Emi ocupa entonces el espacio público de la villa, en tanto que su muerte produjo una ruptura. Ruptura sucedida de replanteamientos sobre los vínculos que unen a los jóvenes. La amistad, lazo privilegiado y altamente valorado por las y los jóvenes en gran parte de las situaciones de sus vidas, estructura sus cotidianeidades y subjetividades, sus lazos, la obtención de recursos y placeres. Aquello que la muerte de Emiliano puso en escena residió precisamente en la traición de los códigos asociados a la amistad.

La presencia de la gruta, y de los objetos colocados dentro de ella, se erigieron entonces como recordatorio físico de un pasado conflictivo, de un acto de denuncia, de la posible 
traición a una amistad entre jóvenes, que podría actuar como chispa para reavivar los conflictos tanto como reactualizar el dolor posterior a una muerte tan sentida por todos. Las demostraciones y su territorialización, permitieron demarcar un lugar para colectivizar el dolor, donde la villa puede repensarse y redimirse a sí misma.

El altar familiar de Facundo en la plaza

A Facundo, apodado el Rubio del Pasaje, le gustaba - mucho- la música de cuarteto. Hasta tenía su propia banda. Si bien la Mona Jiménez, al igual que para muchos cordobeses, era su máximo ídolo, el Rubio frecuentaba también otros bailes, entre los que se encontraban los de Damián Córdoba, probablemente por su amistad con uno de los integrantes del grupo. Era imposible no darse cuenta de las preferencias del Rubio al entrar en su habitación aquella tarde de noviembre pocos meses después de lo ocurrido, en ocasión de la entrevista que le haríamos a Viviana, su madre, para la muestra de imágenes. En ese momento conocía a Viviana a través de los medios de comunicación. Poco a poco se iría convirtiendo en una figura pública. Estas circunstancias marcaban ciertas diferencias respecto de la mayoría de los familiares con los que venía trabajando y que, aun perteneciendo a diversas organizaciones sociales, no habían alcanzado la misma preeminencia como activistas; o de otros tantos casos todavía menos conocidos, a los que no hubiera podido acceder sin la intermediación de sus vecinos.

5 Su casa de un barrio del este de la ciudad de Córdoba, compuesta por pocos ambientes, se encontraba en un pasaje, tal como quedara plasmado en el apodo de Facundo. Desde la entrada se podía ver una mesa para dos o tres comensales y de allí dos habitaciones más. "Palermo"15, el perro del Rubio, entraba y salía constantemente. Viviana nos hizo pasar sin demasiados preámbulos a donde se llevaría a cabo la entrevista: su cuarto, conservado tal cual lo dejara Facu por última vez. Entramos tratando de no tocar nada. Me senté sobre la cama, al lado de Viviana.

Recortes de diarios, revistas, un sinnúmero de afiches de Boca Juniors, y escritos a su hija recién nacida, apenas dejaban ver las paredes donde estaban colgados. A cierta incomodidad por tanta presencia del Rubio se le sumó el olor a pintura que Viviana decía aún sentir en los pantalones de obrero que acondicionó sobre la cama, frente a nosotros. Ese mismo que usaría horas antes de desaparecer.

Aquella noche de febrero, después de trabajar todo el día, cenó con su novia y su mamá. Se bañó y se fue al baile de Damián, en el Estadio del Centro. No llevó su celular, porque estaba descargado. Sus amigos lo vieron a la salida y no se supo más de él. Apenas Viviana se dio cuenta de que Facundo no volvía, sospechó de la policía porque ya había sido detenido tres veces por contravenciones. ${ }^{16}$ Viviana nos cuenta:

me despierto a las seis y no estaba en la pieza Facu. Llovía bastante ese día. Lo saco a Palermo y volvemos. Él hacía mucho ruido cada vez que Facu venía, pero esa madrugada durmió toda la noche. Me acuesto de nuevo. A eso de las diez y algo, me desperté con el sol fuerte en la cara, el que sale después de una lluvia fuerte. De ahí fue la preocupación porque no estaba. Ni me había mandado mensaje, aunque sea con otro celular.

Él en realidad iba a los bailes de la Mona, pero ya no iba más porque no podía disfrutar. Los mismos policías los paran, los presionan, y de tanta humillación es que los chicos reaccionan, y cuando reaccionan... pierden. Él tampoco iba al Estadio del Centro porque está cerca de la Central de Policía. Pero ese día estaba con unas amistades nuevas y fueron. 

desapariciones, la de Marcos, su hermano, desaparecido durante la última dictadura cívico-militar en el centro clandestino El Pozo de Banfield, y la de Nati, su cuñada, embarazada de seis meses, desaparecida en la Escuela de Mecánica de la Armada (ESMA). Es decir que con Facundo la figura de la desaparición se hace nuevamente presente en su historia. A partir de su trayectoria, Viviana consiguió construir redes con diversos organismos de derechos humanos ${ }^{17}$ a lo largo del tiempo, que contribuyeron a fortalecer su activismo familiar.

La apelación a la figura de la familia surge constantemente en sus apariciones públicas. El discurso que dio durante la marcha del 24 de marzo de 2013, convocada por los organismos a poco más de un año de la desaparición de Facundo, anuda estos entramados que intento problematizar. Ocupando un lugar privilegiado como una de las oradoras, Viviana tomó el micrófono con firmeza y expresó:

Desde la familia de Facu, a un año y un mes de su desaparición denunciamos que no hay avances. Que sólo se ha buscado, no hay nada, solo más mentiras y dilaciones. El gobernador no nos ha recibido siendo el máximo responsable de que haya un desaparecido en Córdoba y quien debería dar las explicaciones correspondientes a la familia de por qué es posible que haya desaparecido sin tener el apoyo del poder político.... Esta policía cordobesa que por acción u omisión, yo diría más que por 
acción es responsable. Le queremos decir que a Facu lo vamos a encontrar aunque me cueste la vida [aplausos]. Hace mucho dijimos Nunca Más, no sólo estamos con los 30.000 desaparecidos... hermano querido, donde quiera que estés, Marcos, te quiero. Nati. Sin Facundo, sin Luciano, sin Julio, sin Yamila, y sin tantos otros: no hay Nunca Más.

Ella no habla en su nombre como madre de Facundo. Lo hace a título de la familia. Es desde allí que se presenta e interpela al gobierno preguntando qué pasó con Facundo. Viviana, separada, tiene además un hijo en el extranjero y una hija fallecida en un accidente de tránsito a los pocos años de vida -muerte a la que no refiere como denunciable-. Ese "nosotros inclusivo" consigue incorporar en su reclamo público especialmente a la hija de Facundo, por entonces de apenas unos meses de vida. Establecer un puente, como Viviana lo hace, entre pasado y presente desde la apelación al Nunca Más, devela su propia trayectoria. Es decir que con Facundo la figura de la desaparición se hace nuevamente presente. La alusión que hace Viviana al Nunca Más no es entonces meramente alegórica sino que responde a su propia biografía, y a los modos legitimados de devenir "víctima" en las redes que se tejieron en torno a su caso.

¿Cómo territorializar entonces la desaparición? ¿Cómo visibilizar su ausencia, su ocultamiento, como una responsabilidad de las agencias del Estado? ¿Cómo construir un altar o una gruta cuando se está desaparecido? Si observamos las experiencias de otros familiares de desaparecidos encontramos que sin la existencia de una sepultura y, por lo tanto, de una tumba (Da Silva Catela, 1998), se diversifican los espacios de encuentro y de conmemoración, los altares, los álbumes fotográficos familiares, los lugares donde se presume esa persona ha estado.

En este caso, y recién casi cinco años después de su desaparición, Viviana, junto a organismos de derechos humanos, decidieron armar un altar en la plaza del barrio donde Facu iba a jugar de pequeño. ¿Qué imágenes se incluyeron allí? ¿Por qué construir el altar en la plaza y no en la casa? ¿Por qué un altar familiar y no una gruta? 


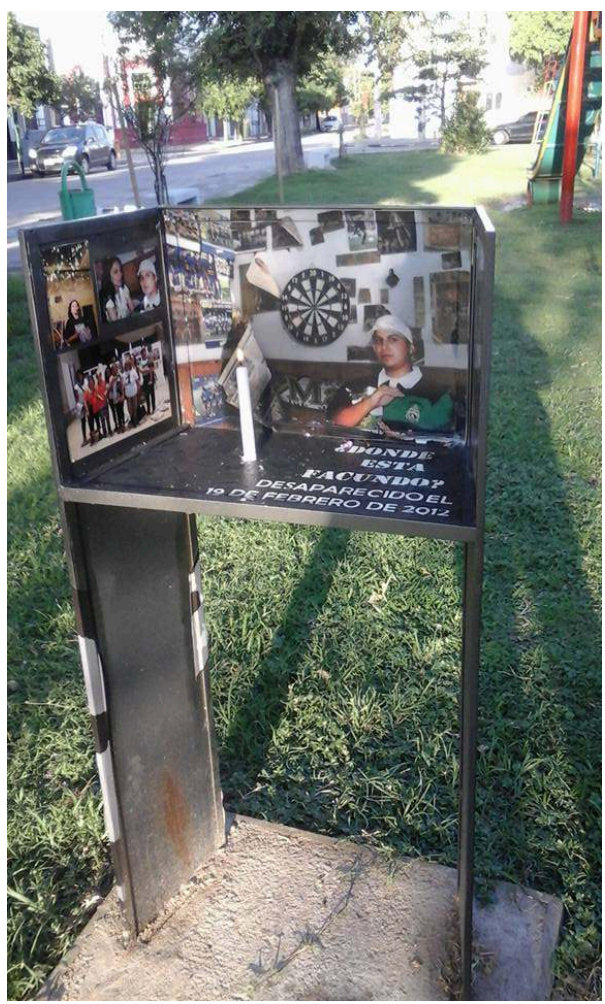

IMAGEN 5. Viviana llevó y prendió la velita mientras tomábamos una foto. Imagen tomada por Ayelén Koopmann

El altar fue construido principalmente con las fotos de su cuarto, de su lugar privado, que fijan la presencia/ausencia del Rubio en aquellas paredes. La significatividad de esa ausencia y desaparición solo puede ser denunciada desde la fuerte presencia de Facundo en la vida de familia, en su casa, en su habitación, en la plaza donde jugaba. Allí Viviana se dirige con su nieta para encenderle una velita y cada vez que van, encuentran caramelos y bebidas que han sido dejados por los amigos del barrio.

La imagen principal del altar muestra dónde falta Facundo, dónde es querido y extrañado. Sin que impliquen respuestas mecánicas, podemos decir que, ante las acusaciones morales que le destinan cierto merecimiento a su desaparición, se le contraponen entonces pruebas de apego a valores y vínculos tradicionales legitimados socialmente.

80 Este altar familiar ubicado "puertas afuera", es decir "fuera de lugar", permite entonces ponderar la desaparición por sobre su posible muerte -tal como lo haría una gruta-. Consigue además mostrar, en todo su espesor, que la familia lo busca, lo extraña, lo espera. Es decir que el altar que sería solo íntimo, familiar, resulta en este caso despojado de lo privado, dislocado de ese hermetismo, y colocado en el ámbito más colectivo. Así expuesto, familiariza el reclamo y lo inscribe en el entramado de los lazos más primordiales ya consagrados.

81 Tal como lo han señalado diversos autores, el trabajo del movimiento por los derechos humanos en la Argentina ha permitido relativizar la dicotomía de aquellos análisis que reducen lo familiar al ámbito privado, en oposición a la esfera pública y al espacio de la política. Sacando lo familiar de la esfera privada, muchas agrupaciones civiles se han definido públicamente a partir de una relación de consanguinidad existente o declarada con las propias víctimas del terrorismo de Estado (Vecchioli, 2005). El uso del pañuelo 
blanco de las Madres de Plaza de Mayo, que simboliza el pañal de tela que usaban los bebés para representar así a sus hijos desaparecidos, podría funcionar como una metáfora de este proceso.

En este caso, es el altar familiar llevado a la plaza el que nuevamente nos interpela a repensar la noción de familia en un doble sentido: como dije, restituyendo a Facundo acusado de dedicarse a vender drogas- al entramado familiar que lo transforma en una persona "que importa". Y, a su vez, respecto de la familia como un principio de adhesión política consagrado en nuestro país para la intervención política (Pita, 2005 y 2010, Da Silva Catela, 2008, Vecchioli, 2005, Bermúdez, 2017). Consideraciones finales

Este texto pretende contribuir a mostrar las múltiples y simultáneas actividades que desarrollan los familiares durante el proceso de búsqueda de justicia y de duelo, y el trabajo social y simbólico para resignificar gran parte de las muertes que atraviesan las personas de sectores populares.

En los altares y, especialmente en las grutas, podríamos decir que el "barrio habla" (Eilbaum, 2010), convirtiéndose en aquellos lugares de enunciación donde las memorias pueden ser narradas para evitar la muerte social (Thomas, 1993).

Hemos visto en este artículo cómo la construcción de altares y especialmente de grutas forma parte de un proceso de territorialización de la muerte violenta en las últimas décadas que implica, por un lado, la resignificación de valores colectivos "convencionales" que con la muerte o la desaparición han sido confrontados. Como vimos, las muertes han sido inscriptas dentro de discursos hegemónicos y normativos relacionados con el trabajo, la amistad, la familia. Tanto la presencia como la ausencia de altares y grutas en los territorios pueden pensarse como "portales" de los márgenes, es decir como lugares privilegiados para comprender cómo los sectores populares lidian con la muerte, disputan los sentidos que la sociedad le destina a sus muertos y apelan a valores "convencionales" para hacerlo.

En el caso del Güeré, se buscó legitimar al joven -y al barrio mismo- en las contiendas morales en las que se disputan los casos, desde la figura del trabajador sacrificado. Por su parte, la amistad y los códigos a ella vinculados, fueron interpelados colectivamente a partir de la muerte de Emiliano, un joven que alternaba actividades "legales" e “ilegales" de la economía informal. Su valentía y buen corazón fueron destacados en la gruta como contracara de la figura del traidor. El altar familiarizado de Facundo, finalmente, se dirigió a reforzar su ausencia y desaparición como violencia de Estado, buscando superar las clasificaciones que circunscriben su aparente muerte a un ajuste de cuentas, como una muerte merecida. Rodrigo, como hemos visto, aún no tiene su gruta.

Así, las grutas y altares moralizados operan reinscribiendo territorialmente al muerto en la esquina, en el pasaje, en la calle, esto es, fijando la presencia de los jóvenes en sus territorios, pero a través de movimientos de resignificación de los acontecimientos, valores y posiciones. En tanto que muestran complejos procesos de moralización y devoción en los que se conjugan demostraciones emotivas y amorosas intergeneracionales, tiempos colectivos de duelo, versiones locales en torno a lo sucedido y activismo político de los grupos populares contemporáneos, no podríamos considerarlas como prácticas "espontáneas" (Arenas, 2015), ni meramente reactivas a las contiendas morales que atraviesan las muertes. Pero que sin embargo surgen en un 
contexto de progresiva normalización de las muertes violentas de los jóvenes empobrecidos.

Por último, sugiero advertir que la operación que consiste en apelar a valores "convencionales" no implica necesariamente que solo sea en pos de universalizar el reclamo dentro de aquellas contiendas morales en las que las muertes son juzgadas, sino que lejos de responder linealmente a las reputaciones que los sectores hegemónicos les deparan a los sectores populares, los valores "convencionales" continúan formando parte de sus experiencias y entran dentro de sus expectativas y horizontes posibles. Y qué ritual de pasaje, sino la muerte, para inscribir a esa persona dentro de entramados y parámetros conocidos y legitimados socialmente donde la muerte, por fin, importe.

\section{BIBLIOGRAPHY}

Aguiar Bittencourt, L. (2004). Algumas considerações sobre o uso da imagem fotográfica na pesquisa antropológica. En B. Feldman-Bianco y M. Moreira Leite (Orgs.). Desafios da imagem. Fotografia, iconografia e vídeo nas ciências sociais. (197-2012). São Paulo: Papirus Editora.

Arenas, S. (2015). Luciérnagas de la memoria. Altares espontáneos y narrativas de luto en Medellín, Colombia. Revista Interamericana de Bibliotecología, 38(3), 189-200.

Balbi, F. (2007). De leales, desleales y traidores. Valor moral y concepción de política en el peronismo. Buenos Aires: Editorial Antropofagia.

Bermúdez, N. (2018). Muertos vivientes. Una etnografía sobre la proliferación de iconografías en torno a los jóvenes muertos violentamente en sectores populares de Córdoba (Argentina). Revista Sociedad y Religión, XXVIII(49), 49-72.

Bermúdez, N. (2016). De "morir como perros" a "me pinto sólo cuatro uñas". Una mirada antropológica sobre crueldad, moralidad y política en muertes vinculadas a la violencia institucional en Córdoba (Argentina). Publicar en Antropología y Ciencias Sociales, XIV(20), 9-28.

Bermúdez, N. (2017). Sin Facundo no hay Nunca Más. Trayectorias, contiendas morales y opacidades en la producción social de una víctima "no inocente" en Córdoba (Argentina)". Papeles del Ciec. Centro de Estudios sobre la Identidad Colectiva, vol. 2017 (2), 1-26.

Bermúdez, N. (2015). Entre padres y hermanos. Lazos de sangre y prácticas políticas de los allegados a muertos en contextos de violencia (Ciudad de Córdoba, Argentina), AIBR, Revista de Antropología Iberoamericana, Septiembre, 377-399.

Bermúdez, N. (2014). Moralidades de la inseguridad. Entramados locales y principios de adhesión política en casos de muertes violentas. En N. Bermúdez y M. E. Previtali (Orgs.), Merodear la ciudad. Miradas antropológicas sobre espacio urbano e inseguridad en Córdoba, (pp. 105-126). Córdoba: Ediciones del IDACOR-CONICET.

Carozzi, M. J. (2005). Revisitando La Difunta Correa: nuevas perspectivas en el estudio de las canonizaciones populares en el Cono Sur de América. Revista de Investigaciones Folclóricas, XX, $13-21$. 
Carozzi, M. J. (2006). Antiguos difuntos y difuntos nuevos. Las canonizaciones populares en la década del 90. En D. Míguez y P. Semán (Eds.), Entre santos, cumbias y piquetes. Las culturas populares en la Argentina reciente, (pp. 97-110). Buenos Aires: Editorial Biblos.

Cozzi, E., Font E., y Mistura, M.E. (2014). Desprotegidos y sobrecriminalizados: interacciones entre jóvenes de sectores populares, policía provincial y una fuerza de seguridad nacional en un barrio de la ciudad de Rosario. Revisa Derechos Humanos. Editorial del Ministerio de Justicia y Derechos Humanos de la Nación, 3-30.

Chaves, M. (2010). Jóvenes, territorios y complicidades. Una antropología de la juventud urbana. Buenos Aires: Espacio Editorial.

Da Silva Catela, L. (2008). Derechos humanos y memoria. Historia y dilemas de una relación particular en Argentina. Teoria e Cultura, 3(1/2), 9-20.

Da Silva Catela, L. (1998). Sin cuerpo, sin tumba. Memorias sobre una muerte inconclusa. Historia, Antropología y Fuentes Orales, 20, 87-104.

Das, V. y Poole, D. (2008). El estado y sus márgenes. Etnografías comparadas. Cuadernos de Antropología Social, 27, 19-52.

Eilbaum, L. (2010). O bairro fala: Conflitos, moralidades e justiça no conurbano bonaerense (tese doutorado). PPGA, UFF.

Epele, M. (2007). Etnografía, fragmentación social y drogas: hacia una política de las miradas. Etnografías Contemporáneas, 3, Septiembre 2007, UNSAM, Buenos Aires.

Epele, M. (2010). Sujetar por la herida. Una etnografía sobre drogas, pobreza y salud. Buenos Aires: Paidós.

Fidanza, J. (2015). Sensación de inseguridad: la cobertura de la devoción a San La Muerte en medios de prensa escrita. Sociedad y Religión: Sociología, Antropología e Historia de la Religión en el Cono Sur, $x x v(44), 90-123$.

Flores Martos, J. A. (2014). Iconografías emergentes y muertes patrimonializadas en América Latina: Santa Muerte, muertos milagrosos y muertos adoptados. AIBR Revista de Antropología Iberoamericana, IX (2), 115-140.

Frigerio A. (2016). San La Muerte en Argentina: usos heterogéneos y apropiaciones del "más justo de los santos" En A. Hernández (Coord.), La santa muerte. Espacios, cultos y devociones, (pp. 253-274). México: El Colegio de la Frontera.

Hathazy, P. (2014). Inseguridades interpeladas: políticas contra el crimen y ciudadanías en la Córdoba neoliberal. En N. Bermúdez y M. E. Previtali (Orgs.), Merodear la ciudad. Miradas antropológicas sobre espacio urbano e "inseguridad" en Córdoba, (pp. 27-55). Córdoba: Ediciones del IDACOR-CONICET.

Kessler, G. (2009). El sentimiento de inseguridad. Buenos Aires: Siglo XXI Editores.

Malinowski, B. (1966) 皆1986㹂 Crimen y costumbre en la sociedad salvaje. Barcelona: Planeta Agostini.

Martín, E. (2007). Gilda, el ángel de la cumbia. Prácticas de sacralización de una cantante argentina. Religião e Sociedade, 27(2), 30-54.

Míguez, D. (2008). Delito y cultura. Los códigos de la ilegalidad en la juventud marginal urbana. Buenos Aires: Editorial Biblos. 
Míguez, D. (2012). Canonizaciones y moralidades en contextos de pobreza urbana. Las lógicas del orden y la transgresión en la Argentina de fines del siglo XX. Revista Cultura y Religión, VI (1), 241-274.

Míguez, D., Semán, P. (2006). Diversidad y recurrencia en las culturas populares actuales. En Entre Santos Cumbias y Piquetes. Las culturas populares en la Argentina reciente, (pp. 11-32). Buenos Aires: Biblos.

Pereira Leite M. (2004). As mães em movimiento. En P. Birman y M. Pereira Leite (Orgs), Um Mural para a Dor. Movimentos cívico-religiosos por justiça e paz, (pp. 141-190). Rio de Janeiro: UFRGS Editora.

Pita, M. (2010). Formas de morir y formas de vivir. El activismo contra la violencia policial. Buenos Aires: Ediciones del Puerto/CELS.

Pita, M. (2005). Mundos morales divergentes: los sentidos de la categoría familiar en las demandas de justicia ante casos de violencia policial. En S. Tiscornia y M. Pita (Eds.), Derechos humanos, tribunales y policías en Argentina y Brasil, (pp.205-235). Buenos Aires: Antropofagia.

Previtali, M. (2018). Hacerse jóvenes andando en la calle. Sociabilidades y violencias en espacios liminales de Villa El Nailon, Córdoba. Cuestiones Criminales, 1(1), 77-106.

Segato, R. (2006). En busca de un léxico para teorizar la experiencia territorial contemporánea. Politika: Revista de Ciencias Sociales, 2, 129-148.

Semán, P. (1997). Religión y cultura popular en la ambigua modernidad latinoamericana. Nueva Sociedad, 149, 130-145.

Taussig, M. (1992). La magia del Estado: María Lionza y Simón Bolívar en la Venezuela contemporánea. En E. Gutiérrez y otros (Eds.), De palabra y obra en el Nuevo Mundo, (pp. 489-517). México: Siglo XXI.

Thomas, L.-V. (1993). Antropología de la muerte. México: Fondo de Cultura Económica.

Vecchioli, V. (2005). La nación como familia. Metáforas políticas en el movimiento argentino por los derechos humanos. En S. Frederic y G. Soprano (Comps.), Cultura y Política en Etnografías sobre la Argentina, (pp.1-22). Buenos Aires: Editorial de la Universidad Nacional de Quilmes.

\section{NOTES}

1. Este texto es una reelaboración de la ponencia "The plots of deaths and disappearances of young people and their mothers in popular sectors (Córdoba, Argentina)", presentada en las Jornadas de Género y Crimen organizado, UNDOC; Florencia, Italia, 2018.

2. De ahora en más las categorías nativas se marcarán en cursiva.

3. Algunos de los familiares que participan de la muestra pertenecen principalmente a la Coordinadora Antirrepresiva y a la Mesa de Trabajo por los Derechos Humanos, ambas en Córdoba (Argentina). Titulada "Entre altares y pancartas. Imágenes, luchas y memorias de la violencia institucional en Córdoba", la muestra tiene una modalidad itinerante y congrega casos producidos desde el retorno a la democracia hasta el presente. El objetivo principal consiste en visibilizar tanto las actividades vinculadas a lo que los familiares llaman "la lucha", como aquellas prácticas conmemorativas y narrativas desplegadas en los espacios privados y públicos, especialmente en torno a altares y grutas.

4. Frigerio (2016) sugiere que la creciente divulgación de la devoción a San La Muerte se encuentra vinculada a la del Gauchito Gil, uno de los bandoleros de origen correntino santificado popularmente. Los relatos sobre su vida dan cuenta de que el Gauchito fue capturado por la 
policía, pero como era devoto de San La Muerte debieron colgarlo de un árbol y desangrarlo para que muriera. Los autores coinciden en señalar que esta vinculación se produce más frecuentemente en los segmentos más populares, en tanto que los más cercanos a las clases medias demandan por los desvíos que se realizan de las ortodoxias de sus tradiciones religiosas (Frigerio, 2016). Asimismo, los medios contribuyen a estigmatizar estas devociones (Fidanza, 2015).

5. Eloísa Martín (2007) propone entender los vínculos que los fans establecen con la cantante Gilda como prácticas de sacralización, superando así las concepciones dualistas de lo sagrado en tanto opuesto a lo profano. Prácticas que pasan por "estar con ella", por "ayudar a la gente", o "mantener viva su memoria" en diferentes situaciones y espacios, y cuya inexistencia harían que Gilda se muera definitivamente.

6. El lema de la Coordinadora Antirrepresiva es "ni un pibe menos" y está conformada por familiares, madres y hermanas, en su mayoría, de víctimas de gatillo fácil.

7. Zarpar implica haber faltado el respeto al haber ido a la casa con gente de afuera de la villa.

8. Vigilantes o buchones. Esta acusación recae usualmente sobre la policía como una forma de deslegitimar sus prácticas abusivas.

9. Parto en este texto de la noción de territorio "representado y apropiado" de Rita Segato (2006), porque permite pensarlo como apropiación política del espacio. Para Segato, "tiene que ver con su administración y, por lo tanto, con su delimitación, clasificación, habitación, uso, distribución, defensa, y muy especialmente, identificación" (2006, p. 76); pero, sobre todo, retomo la experiencia y la identidad (personal y colectiva) a la que alude la antropóloga.

10. Esta idea está inspirada en Taussig (1992) para quien los portales de Venezuela son puertas al mundo fantástico de la representación histórica de la nación y de América a través de los muertos, y de la fuerza imaginaria del Estado bolivariano.

11. Retomo los aportes de Das y Poole para pensar en los márgenes no como meramente territoriales, sino también "sitios de práctica en los que la ley y otras prácticas estatales son colonizadas mediante otras formas de regulación que emanan de las necesidades apremiantes de las poblaciones, con el fin de asegurar la supervivencia política y económica" (2008, p. 24).

12. Sigo aquí los aportes de Fernando Balbi (2007) para pensar en estos procesos de moralización. Balbi sugiere atender a una serie de recaudos metodológicos para tratar de remitir los valores morales a factores sociales menos abstractos, tales como instituciones, entramados de relaciones y procesos sociales específicos, apegándonos en definitiva a los descubrimientos propiamente etnográficos, para evitar adjudicarlos a meras abstracciones de origen difuso.

13. Alternaba actividades delictivas con trabajo informal.

14. Entre unos matorrales había una cruz negra de hierro. Algunos vecinos me habían dicho que pertenecía a alguien que había muerto en las vías del tren que atraviesa la villa hacía muchos años. Sin embargo, no encontré ningún pariente ni vecino que supiera su nombre o que aún visitara la cruz.

15. El nombre hace alusión al jugador de fútbol boquense Martín Palermo que el Rubio admiraba. 16. La mayor cantidad de detenciones y controles policiales en la provincia se producían bajo los artículos 98, 53 y 45 del Código de Faltas -actual Código de Convivencia-, vinculados especialmente a la figura del merodeo. Organizaciones sociales, organismos de derechos humanos y diversos especialistas en la temática han denunciado la arbitrariedad de estas detenciones dirigidas casi exclusivamente hacia los jóvenes provenientes de sectores populares.

17. Especialmente la Mesa de Trabajo por los Derechos Humanos a la que pertenece Viviana, pero también La Coordinadora Antirrepresiva y la Campaña contra la violencia institucional, nuclean gran parte de los casos vinculados a víctimas de violencia policial y/o institucional de los sectores populares cordobeses. La Campaña se presentó públicamente en 2012 y, según sostiene, funciona a través de una red de abogados y estudiantes de derecho, promotores y voluntarios, con un 
significativo trabajo territorial. Algunas actividades están co-coordinadas con la Mesa de Trabajo por los Derechos Humanos.

\section{ABSTRACTS}

Within the framework of the proliferation of altars, murals and memorials in the popular sectors of Cordoba built to honor young people killed in contexts of violence, in this article I propose to analyze how altars and memorials are established in some way as "portals" of the margins, that is, as moralized territories where the popular groups deal with death, dispute the senses that society destines for their dead and appeal to conventional values to do so. By virtue of degrading daily experiences throughout their life trajectories but particularly after a death or disappearance, families assume, reflect, answer and question those moral disputes that cross their cases. The fact that these groups appeal to conventional values does not imply that it is only on pursuit of universalizing their claims, and far from responding linearly to the reputation that the hegemonic sectors hold of them, such values are part of their experiences and fall within their expectations and possible horizons. And what a ritual passage, buth death, to enroll that person within socially known and legitimated frameworks and parameters. This paper is the result of an ethnographic investigation that I have been developing since 2007 and of intervention activities between the university and different organizations with relatives of victims for the creation of an itinerant sample of images.

En el marco de la proliferación de altares, murales y grutas en los sectores populares cordobeses construidos para homenajear a los jóvenes muertos en contextos de violencia, en este artículo propongo analizar cómo los altares y las grutas se establecen de alguna manera como "portales" de los márgenes, es decir, como territorios moralizados donde los grupos populares lidian con la muerte, disputan los sentidos que la sociedad le destina a sus muertos y apelan a valores "convencionales" para hacerlo. A fuerza de degradantes experiencias cotidianas a lo largo de sus trayectorias de vida pero particularmente tras una muerte o desaparición, los familiares asumen, reflexionan, contestan y cuestionan aquellas contiendas morales que atraviesan sus casos. Que en estos grupos se apele a valores "convencionales" no implica que solo sea en pos de universalizar el reclamo, sino que lejos de responder linealmente a las reputaciones que los sectores hegemónicos les deparan, tales valores forman parte de sus experiencias y entran dentro de sus expectativas y horizontes posibles. Y qué ritual de pasaje, sino la muerte, para inscribir a esa persona dentro de entramados y parámetros conocidos y legitimados socialmente donde la muerte "importe". Este escrito es el resultado de una investigación etnográfica que vengo desarrollando desde 2007 y de actividades de intervención entre la universidad y distintas organizaciones con familiares de víctimas para la creación de una muestra de imágenes itinerante.

\section{INDEX}

Keywords: Altars, memorials, violent deaths, moralization, politics.

Palabras claves: Altares, grutas, muertes violentas, moralización, política 


\section{AUTHOR}

\section{NATALIA BERMÚDEZ}

Instituto de Antropología de Córdoba - Consejo Nacional de Investigaciones Científicas y Técnicas - Departamento de Antropología - Facultad de Filosofía y Humanidades, Universidad Nacional de Córdoba

Correo electrónico: natibermudez@yahoo.com.ar 